\title{
Prevalence of Dental Caries among adolescence of Dhanusha District, Nepal
}

\author{
Yadav K*1, Prakash $S^{2}$, Khanal S ${ }^{3}$, Singh JK ${ }^{4}$
}

Dept. of Microbiology, Clinical Pathology Laboratory, Janaki Medical College, Janakpur

$1^{*}$ Medical Microbiologist \& Lecturer, Krishna Medical Technical Research Center, Janakpur
${ }^{2}$ Assistant Professor, Department of Biochemistry, Janaki Medical College, Janakpur
3Lecturer, Department of Microbiology, National College, Kathmandu
${ }^{4}$ Assistant Professor, Department of Community Medicine, Janaki Medical College, Janakpur

ABSTRACT

Background and Objectives: In developing countries like Nepal, the oral health system is currently in transition phase facing a high prevalence of dental caries. It has significant social impact in important life activities which hinders the achievement and maintenance of good oral health due to lack of dental awareness in all age groups. Streptococcus mutans is the most predominant organism to cause dental caries. Therefore, the present study was designed to determine the prevalence of dental caries and to identify its etiology among adolescence.

Material and Methods: This cross-sectional study was carried by following Standard protocols of Bergey's Manual of Systematic Bacteriology to isolate and identify the organism. The data was analyzed using SPPS 17.0 and Microsoft excels 2007 which was considered as statistically significant at $p$-value $<0.05$.

Results: The prevalence of dental caries in adolescent was found to be 33\%. The highest numbers of patients having dental caries were in the age group of 15-19 in female $(66.32 \%)$ than male (39.70\%). Bacterial growth was observed more in female $(75.60 \%)$ than male $(24.39 \%)$ which was found to be statistically significant $(\mathrm{p}=0.0001)$. S. mutans was found as the most important cause of dental caries. Maxillary region of tooth were more vulnerable to dental caries than mandibular region of tooth. Most of the respondents had once per day brushing habit without fluoridated dentrifice containing tooth paste.

Conclusion: The prevalence of dental caries was found one third of total. S.mutans was the main causes of dental caries and molars tooth are more affected than others.

Key Words: Dental caries, Prevalence, S. mutans, Significant, Maxillary, Molar teeth

\section{INTRODUCTION}

The distribution and severity of dental caries vary in different parts of the world and within the same country or region. Nepal is a developing country with little awareness and practice regarding oral health among Nepalese population and has a high morbidity of dental 
caries in all age groups of both genders. The prevalence pattern of dental caries varies with age, sex, socio economic status, race, geographical location, food habits and oral hygiene practices [1]. Dental caries, a chronic disease refers to the localized destruction of susceptible dental hard tissues by acidic byproducts from the bacterial fermentation of dietary carbohydrates such as sucrose, fructose and glucose which is reversible in its early stages and is recognized as the primary cause of oral pain and tooth loss [2].

In addition, dental caries also results from an ecological imbalance in the equilibrium between tooth minerals and oral biofilms which is also commonly known as plaque $[3,4]$. The biofilm is characterized by microbial activity, resulting in fluctuations in plaque $\mathrm{p}^{\mathrm{H}}$ which is the result of both bacterial acid production and buffering action from saliva and the surrounding tooth structure. As the $\mathrm{p}^{\mathrm{H}}$ falls below a critical value, the demineralisation of enamel, dentine or cementum occurs, while a gain of mineral (remineralisation) occurs as the $\mathrm{p}^{\mathrm{H}}$ increases [4,5]. The process of demineralisation and remineralisation takes place frequently during the day. Over time, this process leads to either caries lesions or the repair and reversal of a lesion [6].

The microbial community of dental caries is diverse and contains many facultatively and obligately anaerobic bacteria belonging to the genera Actinomyces, Bifidobacterium, Eubacterium, Lactobacillus, Parvimonas, Propionibacterium, Enterococcus, Scardovia, Rothia and the members of the mitis, anginosus and salivarius groups of streptococci $[1,7]$. The experience of pain, problem with eating, chewing, discolored or damaged teeth, smiling and communication due to missing teeth have a major impact on people's daily lives and wellbeings [8].
Worldwide, approximately 2.43 billion people (36\% of the population) have dental caries in their permanent teeth. In baby teeth it affects about 620 million people or $9 \%$ of the population [9]. The higher prevalence of dental caries is influenced by the lack of dental awareness and practice in developing countries as compared to developed countries due to geosocio-political, economic factors and inadequate health care assets $[1,10,11]$. It has also been associated with low self- esteem, adverse pregnancy outcomes, increased risk of myocardial infarction, cardiovascular, respiratory, erectile, diabetes complications, cavernous sinus thrombosis and Ludwig angina which can be life-threatening [12-14].

Although some studies on the prevalence of dental caries has been studied in Nepal especially in children by Decayed Missed Filling Teeth (DMFT) index, but no any type of research on dental caries has been conducted in adolesence at Dhanusha district of Nepal. Therefore, this study was conducted to determine the prevalence of dental caries and its etiology among adolescence which can provide health care authorities for further planning, implementation and evaluation in public dental health service by spreading awareness of oral hygiene.

\section{MATERIAL AND METHODS}

\section{Study Design}

The present research work was a crosssectional study which was conducted in the Microbiology laboratory, Department of Clinical Pathology, Janaki Medical College Teaching Hospital (JMCTH), Janakpur, Nepal from April to November, 2014 with the case of 330 clinically ill dental caries patients. All the patients were examined clinically in the dental OPD by Dental Surgeon in the Department of Dentistry. 


\section{Inclusion and Exclusion Criteria}

The adolescence patients reported with complaint of teeth cavities associated with or without pain, pus discharge and biofilm deposits or staining in the teeth were included. Caries free dental patients and those having dental caries with age less than 9 years and more than 20 years were also excluded from the study.

\section{Ethical Consideration}

Ethical approval of this study was taken from the Institutional Ethical Committee of National College, Khushibu, Nayabazar, Kathmandu and Department of Microbiology, JMCTH, Janakpur, Nepal. Informed consent was obtained from the participants prior to the study.

\section{Sample Collection and Processing}

A sterile cotton swab was taken and dipped in $1 \%$ glucose solution broth. The swab was squeezed on the walls of clean, dry, sterile test tube and pressed gently on the portion of tooth cavity. Then, the swab was rotated 2-3 times and again dipped in the same tube containing glucose solution broth. Immediately, the tube of glucose broth was incubated at $37^{\circ} \mathrm{C}$ for $3-4$ hours. Media were prepared as instructed by the manufacturer company (Hi-media). A loopful of inoculum from glucose broth was streaked on Blood Agar (BA) and Mac Conkey Agar (MA) plates and incubated at $37^{\circ} \mathrm{C}$ for $24-$ 48 hours. The significant growth of isolates was sub-cultured on Nutrient Agar (NA) and Blood Agar plates which were incubated at $37^{\circ} \mathrm{C}$ for 24 hours. Identification of significant isolates was done by using Standard microbiological techniques as described in the Bergy's manual which involves morphological appearance of the colonies, Gram's staining reactions and biochemical properties especially carbohydrate fermentation test.

\section{Statistical Analysis}

The data were analyzed using statistical software SPSS 17.0 version and Microsoft excels 2007. The p-value $<0.05$ was considered statistically significant.

\section{RESULTS}

Prevalence of Dental caries among Adolescent

Total of 330 dental caries patients attending dental OPD of JMCTH from April to November 2014, of which 160 were adolescent. The prevalence of dental caries in adolescent was found to be $33 \%$. The results are shown in figure 1.

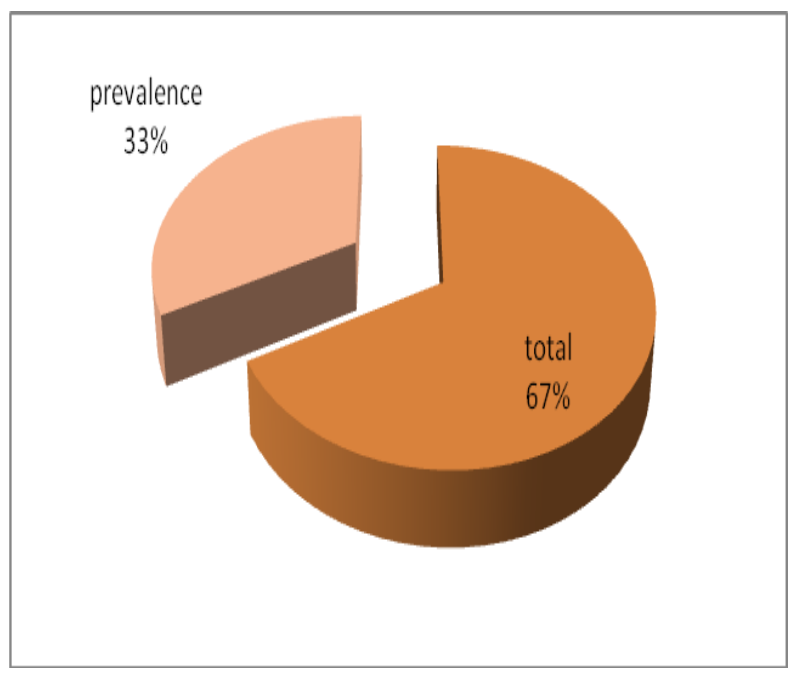

Figure 1: Prevalence of dental caries among adolescent

Age and Gender wise distribution of study population

A total of 160 dental swab samples were collected from adolescence having dental caries. Among them, 62 were male and 98 were female patients. The highest numbers of patients having dental caries were in the age group of $15-19$ in female $(66.32 \%)$ than male (39.70\%). The results are shown in table 1. 
Table 1: Age and genderwise distribution of patients

\begin{tabular}{|c|c|c|c|}
\hline $\begin{array}{c}\text { Age } \\
\text { group } \\
\text { (yrs) }\end{array}$ & Male (\%) & $\begin{array}{c}\text { Female } \\
\mathbf{( \% )}\end{array}$ & Total (\%) \\
\hline $10-14$ & $35(56.45)$ & $33(33.67)$ & $68(42.5)$ \\
\hline $15-19$ & $27(39.70)$ & $65(66.32)$ & $92(57.5)$ \\
\hline Total & $\mathbf{6 2}$ & $\mathbf{9 8}$ & $\mathbf{1 6 0}$ \\
\hline
\end{tabular}

Gender wise distribution of Bacterial Growth

The highest percentage of bacterial growth was observed in female patients with $75.60 \%$ than male $(24.39 \%)$ which was found to be statistically significant $(\mathrm{p}=0.0001)$. The results are shown in table 2 .

Table 2: Pattern of genderwise bacterial growth distribution

\begin{tabular}{|c|c|c|c|l|}
\hline Gender & \multicolumn{2}{|c|}{ Growth } & \multirow{2}{*}{$\begin{array}{c}\text { Total } \\
\text { samples }\end{array}$} & $\begin{array}{l}\text { P- } \\
\text { value }\end{array}$ \\
\cline { 2 - 4 } & $\begin{array}{c}\text { Positive } \\
\text { (\%) }\end{array}$ & $\begin{array}{c}\text { Negative } \\
\text { (\%) }\end{array}$ & & \\
\hline Male & $0(24.39)$ & $2(86.48)$ & $62(38.75)$ & \\
\hline Female & $93(75.60)$ & $5(13.51)$ & $98(61.25)$ & \multirow{2}{*}{0.0001} \\
\hline Total & $\mathbf{1 2 3}$ & $\mathbf{3 7}$ & $\mathbf{1 6 0}$ & \\
& & & & \\
\hline
\end{tabular}

\section{Frequency distribution of Bacterial Isolates}

A total 123 isolates were identified, 93 $(75.60 \%)$ were $S$. mutans followed by 28 $(22.76 \%) \quad S$. aureus and 2 (1.62\%) $K$. pneumoniae. Among all the bacterial isolates, $S$. mutans was found to be primary and most predominant causing dental caries than other isolates. The results are shown as shown in figure 2 .

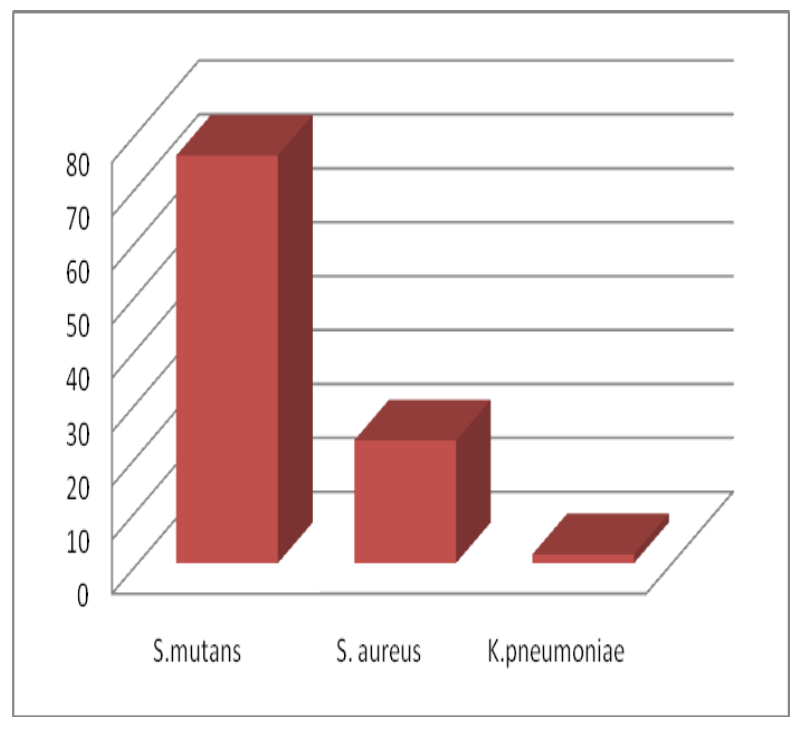

Figure 2: Pattern of bacterial isolates among total study population

\section{Pattern of Brushing habit among Study Population}

Among all respondents, 109 (68.12\%), 36 $(22.5 \%)$ and 15 (9.37\%) had brushing habit once per day, twice per day and occasionally respectively. The results are shown in figure 3.

Table 3: Association between brushing habit and knowledge on dental caries

\begin{tabular}{|c|c|c|c|c|}
\hline \multirow{2}{*}{$\begin{array}{c}\text { Brushing } \\
\text { habit }\end{array}$} & \multicolumn{2}{|c|}{$\begin{array}{c}\text { Knowledge on } \\
\text { dental caries }\end{array}$} & \multirow{2}{*}{ Total } & \multirow{2}{*}{ P- value } \\
\cline { 2 - 4 } & Yes & No & & \\
\hline Occasionally & 3 & 12 & 15 & \multirow{2}{*}{0.0001} \\
\hline Once per day & 98 & 11 & 109 & \\
\hline Twice per day & 27 & 9 & 36 & \\
\hline Total & $\mathbf{1 2 8}$ & $\mathbf{3 2}$ & $\mathbf{1 6 0}$ & \\
\hline
\end{tabular}

Among all respondents, 70 (43.75\%) used fluoridated dentrifice and 90 (56.25\%) hadn't use fluoridated dentrifice. The results are shown in figure 4. 


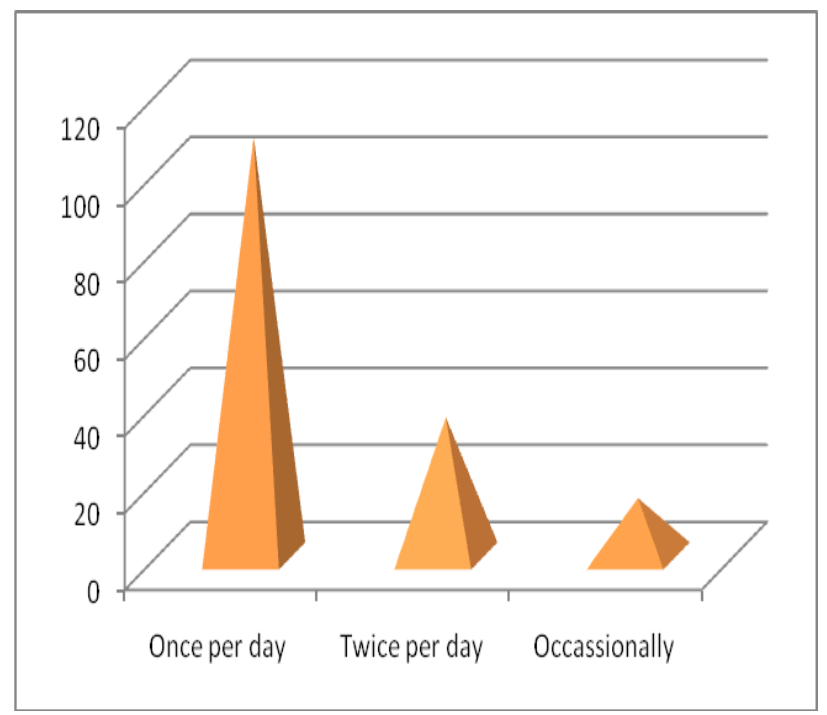

Figure 3: Frequency of brushing habit Distribution of Fluoridated Dentifrice

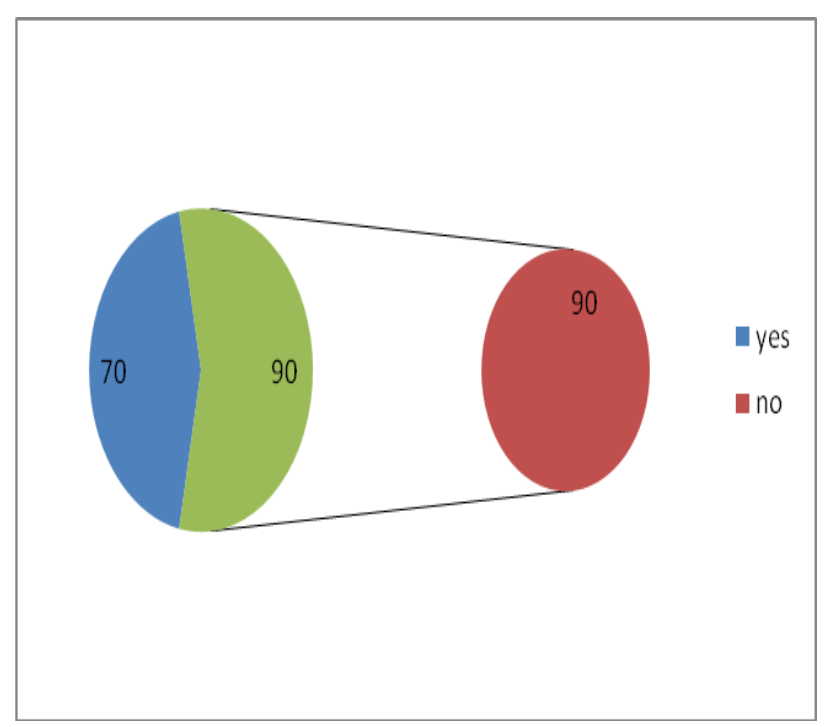

Figure 4: Use of fluoridated dentifrice among the adolescence

\section{Toothwise distribution of Dental Caries}

Most of the respondents had dental caries on the maxillary region than mandibular region of tooth (figure 5). The highest number of dental caries was found on $2^{\text {nd }}$ molar and $1^{\text {st }}$ molar teeth followed by canine in both regions. The results are shown in figure 5 and 6.

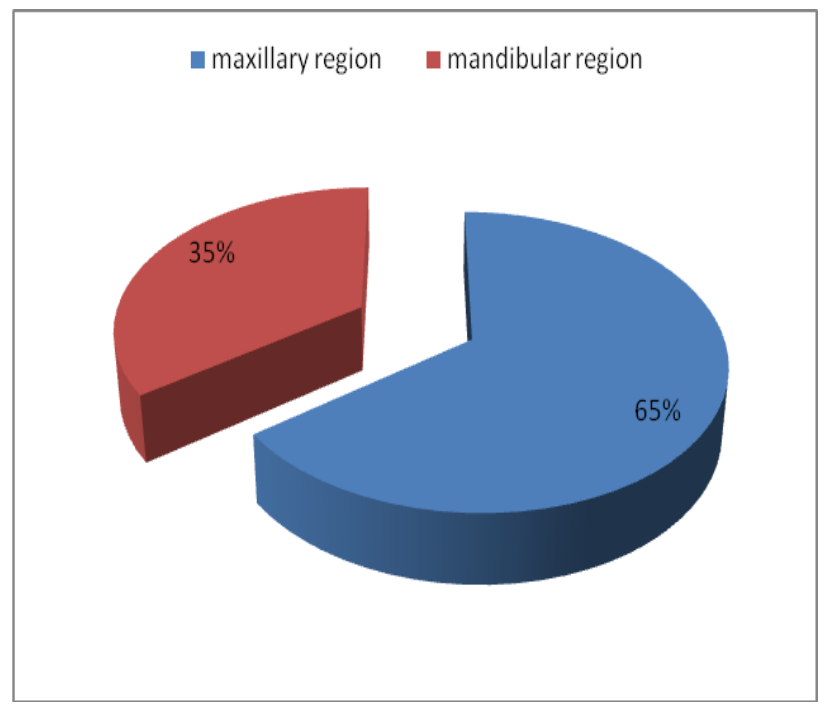

Figure 5: Dental caries distribution in terms of region of tooth

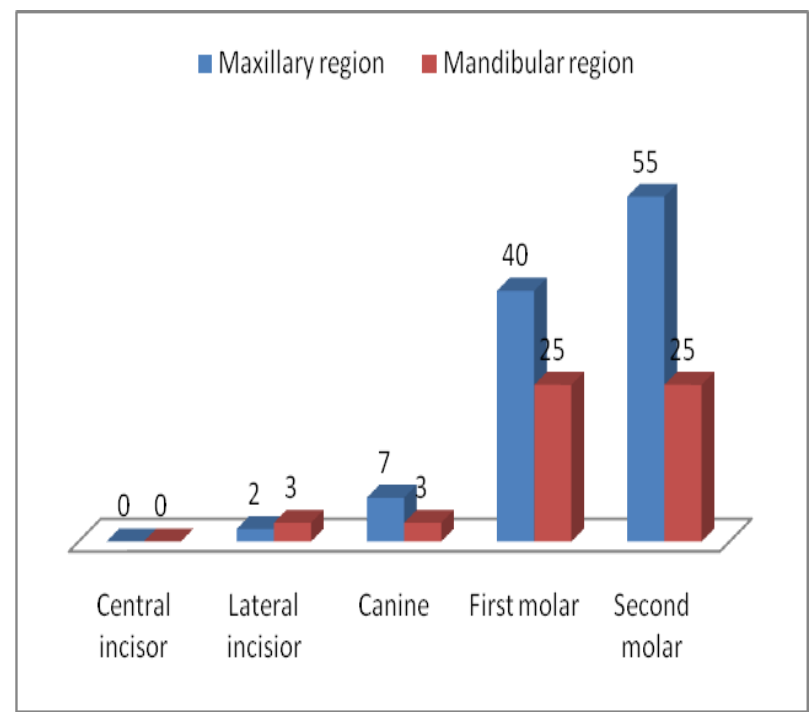

Figure 6: Pattern of tooth wise distribution of dental caries

Association between Brushing habit and Knowledge on Dental caries

Among all respondents, the knowledge on dental caries was found to be highest among the patients having the brushing habit once per day which was statistically significant $(\mathrm{p}=$ 0.0001). The results are shown in table 3 . 
Association between Use of fluoridated dentrifice and knowledge on dental caries

The knowledge on dental caries was found to be highest among the patients who used fluoridated dentifrice which was statistically significant $(p=0.001)$. The results are shown in table 4 .

Table 4: Association between use of fluoridated dentrifice and knowledge on dental caries

\begin{tabular}{|c|c|c|c|c|}
\hline \multirow{2}{*}{$\begin{array}{c}\text { Fluoridated } \\
\text { dentifrice }\end{array}$} & \multicolumn{2}{|c|}{$\begin{array}{c}\text { Knowledge on } \\
\text { dental caries }\end{array}$} & \multirow{2}{*}{ Total } & \multirow{2}{*}{ P-value } \\
\cline { 2 - 3 } & Yes & No & & \\
\hline Used & 56 & 14 & 70 & \multirow{2}{*}{0.001} \\
\hline Not used & 13 & 77 & 90 & \\
\hline Total & $\mathbf{6 9}$ & $\mathbf{9 1}$ & $\mathbf{1 6 0}$ & \\
\hline
\end{tabular}

\section{DISCUSSION}

Despite great improvements in the oral health of population in several countries, it is claimed that poor oral health may have a deep effect on general health, several oral diseases related to chronic diseases as well as value of life. Dental caries is the most studied oral disease in the world, the majority of studies concentrate in school children, with not enough research on the situation of the disease in young adults [15].

The prevalence of dental caries was observed in many studies. As the age advances there was rise in proportion affected by caries. In present study, the prevalence of dental caries in adolescence was found to be $33 \%$. The adolescence age was divided in two age groups i.e. 10-14 and 15-19 years in this study. The dental caries was found to be more in age of 15$19 \quad(57.5 \%)$ than $10-14 \quad(42.5 \%)$ years. According to Subedi B et al (2011) showed the prevalence of dental caries in 12-13 age groups was 53.23\% [16]. Adhikari RB et al (2012) reported caries prevalence in the age group 1114 years was $52.46 \%$ respectively [17]. Dikshit $P$ and Limbu S (2013) recognized caries prevalence in 12-13-year-olds was 41\% [18]. This may be due to the majority of these adolescence consuming sugary foods such as chocolate, candy, jellies, soft drinks, etc. approximately 3-5 times daily, which may be considered one of the most important factors in high caries experience in this group [19].

The present study showed that female (61.25\%) had more dental caries than male (38.75\%). This may be due to female's dental eruption begins six months earlier than males, so they are exposed to cariogenic factors beforehand [20] or due to the increasing sugar consumption, low exposure to fluorides containing toothpaste and poor access to oral health care. According to Subedi B et al (2011) also reported the percentage of caries in female was slightly higher than male [16] which is in accordance with this study.

The present study showed $S$. mutans was the prominent cause of dental caries with $75.60 \%$ followed by $S$. aureus $(22.76 \%)$ and K. pneumoniae (1.62\%). S. mutans collect around the teeth and gums in a sticky, creamy-coloured mass called plaque which serves as a biofilm. Bacteria in a person's mouth convert sugars (glucose and fructose and most commonly sucrose) into acids such as lactic acid through a glycolytic process called fermentation. If left in contact with the tooth, these acids may cause demineralization which is the dissolution of its mineral content [1, 20]. According to Hassan-Olajokun et al (2008) reported $21.21 \%$ S. mutans causing caries in age group of 11-15 [20].

In this study, $S$. aureus was found to be the second most common Gram positive bacteria associated with caries which is 
similar to a study conducted by Fayaz M et al (2014) at Rajah Muthiah Dental College and Hospital, Annamalai University, India [21] and Yadav K and Prakash S (2015) at Janaki Medical College Teaching Hospital, Tribhuvan University, Nepal [1]. $S$. aureus in the aetiology of oral dysaesthesia and mucositis is complicated by the diversity of the normal oral flora and by healthy carriage of $S$. aureus in some patient groups. However, the high rates of $S$ aureus are suspected in patients presenting with symptoms of oral mucosa pain, burning, erythema and swelling. Isolates of $S$. aureus are capable of producing a wide range of exfoilotive toxin and enterotoxin $[1,22]$.

There was a trend to increased recovery of $S$. aureus isolates from more elderly patients in contrast to previous work which found no age related trend for the recovery of $S$. aureus from a healthy population [23]. It is unclear whether this reflects changes in the oral flora associated with increasing age, medication, increased incidence of prosthetic oral devices or referral patterns. The presence of prosthetic devices within the oral cavity, such as acrylic dentures, may encourage the carriage of staphylococci [24]. In studies of denture wearing patients, carriage rates of $S$. aureus have varied from 23$48 \%[25,26]$. The oral carriage of $S$. aureus may be more common than previously recognised and the data collected suggests a reappraisal of the role of $S$. aureus in the health and disease of the oral cavity [27].

This study revealed least number of $K$. pneumoniae associated with dental caries. It is classically thought of as community acquired and occurring in elderly and debilitated population with underlying alcoholism, chronic lung disease or diabetes [1].

This study represents most of the patient brushed their tooth once per day which was the main factor to cause dental caries because after eating and drinking if teeth is not cleaned then there may be the chances of plaque formation quickly by the fermentable bacteria called Streptococcus mutans and the first stages of decay can begin. The present study also showed that 90 (56.25\%) didn't use fluoridated dentrifice. Fluoride containing tooth paste is a naturally occurring mineral which helps in preventing cavities and can even reverse the earliest stages of tooth damage [28].

This study revealed molar tooth (first and second molar) followed by canine was more affected. This may be due to the anatomical structures of tooth which have lots of grooves, pits and crannies that collects food particles. As a result they are harder to keep clean than front teeth where plaque can build and bacteria can thrive between back teeth as molars, producing the acids that destroy tooth enamel [29]. According to the Dikshit P and Limbu S (2013) reported molars and incisior were more affected whereas in this study incisor was not affected due to more resistant to caries which may be due to protection by the tongue and opening of major salivary ducts near the incisors [18]. The present study evidents that the sequence of caries attack follows a specific pattern maxillary being predominantly affected by caries while the mandibular were least affected which is similar to other studies [30, 31].

The present study emphasizes on increasing status of dental caries which helps to determine the appropriate implementing programs to achieve optimal oral health care for 
adolescence. This indicates that there are still shortcomings in the areas of both preventive and curative dental care. More oral health education programs in community and schools must be carried out for the control of oral diseases. These approaches should be combined with family and community-directed preventive programs.

\section{CONCLUSION}

The present study concluded that the prevalence of dental caries in adolescence was $33 \%$. Female had more dental caries than male and was statistically significant. Maxillary molars were more vulnerable to dental caries than mandibular molars. S. mutans was found more responsible to cause dental caries. Most of the respondents had knowledge on dental caries that had once per day brushing habit and those who used fluoridated dentrifice was found to be statistically significant. Acute caries results in severe pain, problem with eating, chewing, smiling and communication whereas chronic caries results in oral and pharyngeal cancers and oral tissue lesions. These are significant health concerns which have a major impact on people's daily lives and well- beings [8]. So, this study was conducted to determine the prevalence of caries on adolescence which was found to be in an increasing trend.

Thus, the current study pointed out that there is a great need for dental and oral health among adolescence. So, it is of high relevance to include preventive strategies with a major public services compromise to give attention to sick teeth, look for the implementation of preventive programs in adolescents and remarking remineralizing substances on hygienic and dietary habits for should be conducted at regular intervals of time in Nepal.

\section{ACKNOWLEDGEMENT}

Authors wish to acknowledge their heartily thanks to all the participants involved in this study, National College, Khushibu, Nayabazar, Kathmandu and Mr. N. P. Yadav, Assist. Prof. in Microbiology, Dr. Ram Snehi Sah, Dental Surgeon as well as Mr. Raj Narayan Yadav, Incharge of Clinical pathology Laboratory, JMCTH, Janakpur, Nepal for their reliable support during this research.

\section{REFERENCES}

1. Yadav K \& Prakash S. Antibiogram profiles against polymicrobial pathogens among dental caries patients at Janaki Medical College teaching hospital, Nepal. Int J of Applied Dental Sci 2015; 1(4): 156-162.

2. Selwitz RH, Ismail AI, Pitts NB. Dental caries. Lancet 2007; 369: 51-59.

3. Fejerskov 0. Changing paradigms in concepts on dental caries: Consequences for oral health care. Caries Res 2004; 38: 182-191.

4. Takahashi N, Nyvad B. Caries ecology revisited: Microbial dynamics and the caries process. Caries Res 2008; 42: 409-418.

5. Manji F, Fejerskov O, Nagelkerke NJ, Baelum V. A random effects model for some epidemiological features of dental caries. Community Dent Oral Epidemiol 1991; 19: 324-328.

6. Featherstone JD. The caries balance: the basis for caries management by risk assessment. Oral Health Prev Dent 2004; 2(1): 259-264.

7. Marsh PD, Nyvad B. The oral microflora and biofilms in teeth. In: Fejerskov 0, Kidd EAM, eds. Dental caries. The disease and its clinical management, 3d edn. Copenhagen: Blackwell Munksgaard 2003; 29-48.

8. Petersen PE, Bourgeois D, Ogwa H, Day SE, and Ndiaye $C$. The global burden of disease and risks to oral health. Bulletin world health organiz 2005; 83(9): 661-669.

9. WHO. Disease and Injury country estimates.2009. Available from : http://www.who.int/healthinfo/global_burden disease/estimates country/en/ (Accessed $6^{\text {th }}$ August 2016) 
10. Zhang J, Xuan D, Fan W et al. Severity and prevalence of plaque-induced gingivitis in the Chinese population. Compend Contin Educ Dent 2010; 31(8): 624-629.

11. Yee R \& Mishra R. Nepal National Oral Health Pathfinder Survey. Kathmandu, Nepal: Oral Health Focal Point; Ministry of Health. HMG Nepal 2004.

12. De-Marchi RJ, Hugo FN, Padilha DM et al. Edentulism, use of dentures and consumption of fruit and vegetables in south Brazilian community dwelling elderly. J Oral Rehabil 2011; 38(7): 533-540.

13. Yadav K, Prakash S, Yadav NP, Sah RS. Multi-Drug Resistance of Bacterial Isolates among Dental Caries Patients. Janaki Med Coll J Med Sci 2015; 3(1): 37-44.

14. Hartmann JR, Richard W. Ludwig's Angina in Children. 2008. Available from: http://www.aafp.org/afp/1999/0701/p109.htm 1 (Accessed 25 May, 2014).

15. Truin GJ, Koning KG, and Kalsbeek H. Trends in dental caries in the Netherlands. Adv Dent Res 1993; 7(1): 15-18.

16. Subedi B, Shakya P, Jnawali M, Paudyal BD, Acharya A, Koirala $S$ et al. Prevalence of Dental Caries in 5-6 Years and 12 - 13 Years Age Group of School Children of Kathmandu Valley. J Nep Med Assoc 2011; 51: 176-179.

17. Adhikari RB, Malla N, Bhandari PS. Prevalence and treatment needs of dental caries in schoolgoing children attending dental outpatient department of a tertiary care centre in western region of Nepal. Nep J Med Sci 2012; 1: 112-115.

18. Dikshit P \& Limbu S. Pattern of dental caries and treatment needs in deciduous dentition of children visiting Kantipur Dental College. J Dent Assoc 2013; 13: 31-35.

19. Lene AFP, Koo H, Bellato CM, Bedi G and Cury JA. The role of sucrose in cariogenic dental biofilm formation. J Dent Res 2008; 85: 878-887.

20. Olajokun HRE, Folarin AA, Olaniran $O$ and Umo AN. The prevalent bacterial isolates of dental caries in school age children attending the Dental Clinic of Oauthc, ILE-IFE. Afri J Clinic Exper Micro 2008; 9: 103-108.

21. Fayaz M, Sivakumaar PK and Melvin JM. Prevalence and Antibiotic Susceptibility Pattern of Dental Biofilm forming Bacteria. Int J Curr Microbiol App Sci 2014; 3: 46-50.

22. Smith SI, Aweh AJ, Coker AO, Savage KO, Abosede DA and Oyedeji KS. Lactobacilli in human dental caries and saliva. Microbio 2001; 105: 77-85.
23. Miyake $Y$, Iwai M, Sugai M, Miura K, Suginaka H, Nagasaka $\mathrm{N}$. Incidence and characterisation of Staphylococcus aureus from the tongues of children. J Dent Res 1991; 70: 1045-1047.

24. MacFarlane TW, Helnarska S. The microbiology of Angular Cheilitis. Brit Dent J 1976; 140: 403406.

25. Percival RS, Challacombe SJ, Marsh PD. Agerelated microbiological changes in the salivary and plaque microflora of healthy adults. J Med Micro 1991; 35: 5-11.

26. Theilade E, Budtz-Jorgensen E. Predominant cultivable microflora of plaque on removable dentures in patients with denture induced stomatitis. Oral Microbiol Immunol 1988; 3: 813.

27. Tawara Y, Honma K, Naito Y. Methicillin resistant Staphylococcus aureus and Candida albicans on denture surfaces. Bull Tokyo Dent Coll 1996; 37: 119-128.

28. Smith AJ, Robertson D, Tang MK, Jackson MS, MacKenzie D \& Bagg J. Staphylococcus aureus in the oral cavity: a three-year retrospective analysis of clinical laboratory data. Brit Dent J 2003; 195: 701703.

29. Jocianelle M, Felix de A, Fernandes, Suyenede OP, Daniele BA, Fábio Correia S, Franklin DSF. Prevalence of dental caries and treatment needs in preschool children in a recently fluoridated Brazilian town. Braz J Oral Sci 2009; 8(4): 185188.

30. Muhammad R, Sadia R. Prevalence and pattern of dental caries in the deciduous dentition. Pakistan Oral \& Dent J 2009; 29(1): 141-144.

31. Saravanan S, Madivanan I, Subashini B, Felix JW. Prevalence pattern of dental caries in the primary dentition among school children. Ind J Dent Res 2005; 16: 140-146.

\section{Correspondence to: Khushbu Yadav}

Lecturer

Krishna Medical Technical Research Center, Janakpurdham, Nepal

E-mail: meetkhushi20@gmail.com 